\title{
ANÁLISIS DEL PRECEDENTE VINCULANTE EN EL CASO HUATUCO HUATUCO Y LA RESPONSABILIDAD ADMINISTRATIVA FUNCIONAL
}

\author{
Binding precedent assay in the Huatuco Huatuco case and \\ the functional administrative responsibility
}

Víctor Lizárraga Guerra*
Universidad Continental

\section{Resumen}

Con base en el análisis de la sentencia del Tribunal Constitucional recaída en el expediente 05057-2013-PA/TC, el autor analiza el impacto de las decisiones del máximo intérprete de la Constitución Política en el régimen del servicio civil. Asimismo, identifica las particularidades de la responsabilidad administrativa funcional y de la actuación de la Contraloría General de la República.

Palabras clave: Responsabilidad administrativa funcional; potestad sancionadora; servicio civil; meritocracia.

\section{Abstract}

Based on the analysis of the judgment of the Constitutional Court relapse in the record 05057-2013-PA/TC, the author analyzes the impact of the decisions of the supreme interpreter of the Constitution in the civil service regime. It also identifies the particularities of the functional administrative responsibility and the General Comptroller of the Republic procedure.

Keywords: Functional administrative responsibility; sanctioning authority; civil service; meritocracy.

* Abogado por la Universidad Pervana Los Andes. Ha realizado estudios de maestría en Derecho Procesal por la Universidad Nacional Mayor de San Marcos. Profesor en la Universidad Continental. Presidente del Instituto Peruano de Derecho Disciplinario. 


\section{INTRODUCCIÓN}

El 2 de junio de 2015 el Tribunal Constitucional (en adelante el Tribunal) publicó en su portal electrónico la sentencia recaída en el expediente 05057-2013-PA/TC calificándola como precedente vinculante, a través de la cual establece determinados criterios que deberán tener en consideración los jueces, al momento de resolver demandas interpuestas por trabajadores públicos despedidos, cuando estos soliciten ser repuestos en su empleo por corresponderles un contrato de trabajo a plazo indeterminado correspondiente al régimen laboral privado.

En el presente trabajo nos abocaremos a realizar un análisis crítico y reflexivo respecto a los criterios desarrollados por el Tribunal en torno al acceso a la función pública, la carrera administrativa y el reconocimiento constitucional de la responsabilidad administrativa funcional a cargo de la Contraloría General de la República (en lo sucesivo CGR).

\section{EFECTOS DEL PRECEDENTE PARA LA ADMINISTRACIÓN PÚBLICA}

\subsection{Ratificación del principio meritocrático en la administración pública}

El precedente vinculante viene promoviendo una discusión respecto a la afectación del derecho al trabajo y el derecho a la protección adecuada contra el despido arbitrario', el cual perjudicaría, tanto en el ámbito económico como, posiblemente, en el desarrollo de su proyecto de vida $^{2}$, a trabajadores que ingresaron sin las formalidades de un concurso público. Asimismo el precedente vinculante contribuye a la profesionalización de la administración pública y al reconocimiento de la meritocracia ${ }^{3}$ como principio rector del acceso a la función pública.

1 Artículos 22 y 27 de la Constitución Política del Perú.

2 Las razones de la discrepancia que el magistrado Blume Fortini manifestó en el fundamento 3.2 de su voto singular refieren que «[el precedente vinculante] convalida un eventual accionar abusivo, lesivo e irresponsable del Estado en la contratación pública laboral, perjudicando injustamente al trabajador y desconociendo las garantías mínimas previstas en el artículo 8 de la Convención Americana de Derechos Humanos, sin tener en cuenta las graves consecuencias socioeconómicas para las personas despedidas y sus familiares y dependientes, tales como la pérdida de ingresos y la disminución del patrón de vida...».

3 La calidad de principio ha sido atribuida por el numeral d del artículo III de la Ley del Servicio Civil, Ley N. ${ }^{\circ}$ 30057, en la que se consigna que «[e]l régimen del Servicio Civil, incluyendo el acceso, la permanencia, progresión, mejora en las compensaciones y movilidad, se basa en la aptitud, actitud, desempeño, capacidad y evaluación permanente para el puesto de los 
El Tribunal ${ }^{4}$ sobre el particular ha precisado: «Esto significa que este principio vincula positivamente al legislador a que la regulación sobre el acceso a toda función pública observe irrestrictamente el principio basilar del acceso por mérito...».

Cabe mencionar que el Tribunal, como parte de la fundamentación legal respecto a la meritocracia, recoge los alcances de la vigencia de la Ley Marco del Empleo Público, Ley N. ${ }^{\circ} 28175$, que señala «el Poder Legislativo ha expedido la Ley 28175, Marco del Empleo Público, en cuyo artículo $5^{\circ}$ establece que el acceso al empleo público se realiza mediante concurso público y abierto, en base a los méritos y capacidad de las personas...». Sobre el particular se debe definir si se encuentra vigente, o no, la Ley $N{ }^{\circ}$ 28175 , teniendo en consideración que el literal b) de la única disposición complementaria derogatoria de la Ley $\mathrm{N} .{ }^{\circ} 30057$ señala que una vez que esta norma se implemente la Ley $\mathrm{N} .{ }^{\circ} 28175$ queda derogada.

Al respecto, es importante señalar que la primera disposición complementaria transitoria de la Ley N. 30057 establece que su implementación es progresiva y en un plazo máximo de seis años. En consecuencia, la Ley N. ${ }^{\circ} 28175$ no se encuentra derogada sino hasta que se culmine el proceso de implementación de la reforma del servicio civil, la cual será declarada por SERVIR 5 . No obstante, se debe precisar que si algunas disposiciones de la Ley $N .^{\circ} 28175$ se oponen a la Ley N. ${ }^{\circ} 30057$, por ser esta una ley posterior, estas disposiciones sí estarían derogadas ${ }^{6}$.

\subsection{El acceso a la función pública}

En la sentencia, identificamos un desarrollo respecto a la función pública, sobre la cual existían contradicciones en la interpretación del Capítulo IV «De la función pública» y los artículos 39 y 42 de la Constitución Política, identificado el problema el Tribunal reconoce que una interpretación constitucionalmente adecuada del concepto de función pública comprende: el desempeño de funciones de todo funcionario y servidor en las entidades públicas ${ }^{7}$, contrario sensu el incumplimiento de funciones configuraría res-

postulantes y servidores civiles».

4 Fundamento 8 de la sentencia del Tribunal Constitucional recaída en el expediente 050572013-PA/TC.

5 Ente rector del sistema administrativo de Recursos Humanos.

6 Conforme se ha precisado en el fundamento 3.13 del Informe Técnico N. ${ }^{\circ}$ 424-2014-SERVIR/GPGSC.

7 Fundamento 8 de la sentencia del Tribunal Constitucional recaída en el expediente 05057 2013-PA/TC. «Sobre el particular, cabe mencionar que el Tribunal Constitucional ha sostenido que una interpretación constitucionalmente adecuada del concepto "función pública" 
ponsabilidad administrativa disciplinaria ${ }^{8}$; es decir, el Tribunal reconoce la concepción amplia del término función pública, recogido por normas nacionales $^{9}$ e internacionales ${ }^{10}$, entendiéndolo como toda actividad realizada por personas naturales en nombre del Estado cuyo fin está encaminado al logro de los fines esenciales del mismo.

En ese sentido, el Tribunal se aleja de la tendencia tradicional que entendía la función pública desde una perspectiva contractual, otorgando el estatuto de la función pública como una relación estatuaria, a través del cual el funcionario o servidor está sometido al cumplimiento de sus obligaciones en cumplimiento del desempeño de las actividades: «[d]e ahí que se diga que el funcionario no tiene con la Administración una relación contractual, sino estatutaria. Es decir, que queda encuadrado desde su nombramiento hasta la extinción del vínculo profesional en el marco de un estatuto público, que fija en cada momento sus derechos, deberes y responsabilidades». ${ }^{11}$

Además, el Tribunal en esta parte efectúa un desarrollo didáctico respecto al derecho de acceso a la función pública el cual comprende: a) la función pública representativa y b) la función pública no representativa, respecto al primero se encuentran los cargo políticos desde las más altas magistraturas, como el de congresistas, el del presidente de la república, y alcanza hasta alcaldes o regidores. En ese sentido, el Tribunal, a través del desarrollo del concepto amplio de función pública, habilita la posibilidad de procesar disciplinariamente a todo funcionario con «cargo» que ejerce funciones de representación política. A la fecha existe un vacío normativo y deficiente tipificación, tal como lo ha reconocido SERVIR, en el fundamento 3.9 del Informe Técnico 311-2013-SERVIR/GPGSC respecto al procedimiento administrativo disciplinario de alcaldes y regidores.

«Nótese que la norma transcrita [Ley Orgánica de Municipalidades] no define qué es una falta grave ni prevé tampoco un listado de conductas o actuaciones que pudieran ser calificadas como "graves" (ni se indica en el resto de disposiciones de la Ley N. ${ }^{\circ} 27972$ ); por el contrario, en la referida norma tan solo se señala que la falta grave se configura "de acuerdo" a lo que establezca el reglamento interno del Concejo Municipal. Corresponde entonces a los Concejos Municipales tipificar adecuadamente las conductas que ameritan la suspensión del cargo».

exige entender de manera amplia, esto es, desde el punto de vista material como el desempeño de funciones en las entidades públicas del Estado...».

8 Sobre la naturaleza de la responsabilidad administrativa disciplinaria nos encargaremos más adelante.

9 Código de Ética de la Función Pública.

10 Convención Interamericana contra la Corrupción.

11 Sánchez, Miguel. Derecho de la función pública. Madrid: Tecnos, 2013, p. 18. 
En consecuencia, es necesario retomar la discusión sobre la necesidad de aprobar un código disciplinario único ${ }^{12}$, a fin de sancionar el incumplimiento de sus funciones a las autoridades que ostentan un cargo político, el cual debería estar a cargo de la CGR. Cabe mencionar, que se encuentra en comisión el Proyecto de Ley 2528-2013-CG ${ }^{13}$, a través del cual se busca ampliar facultades sancionadoras a la CGR contra autoridades elegidas por elección popular, tales como alcaldes, regidores, gobernadores regionales y consejeros regionales.

\subsection{Sobre la carrera administrativa}

En estos últimos tiempos se vienen identificando (portal electrónico del Tribunal) demandas de inconstitucionalidad contra ordenanzas regionales y municipales que reconocían procedimientos administrativos disciplinarios, así como derechos y obligaciones de trabajadores del sector público, las cuales contravienen con la Constitución y la ley. El argumento de los gobiernos subnacionales se fundamenta en su autonomía normativa y política; sin embargo, con el precedente el Tribunal ha definido expresamente que solo con normas con rango de ley, aprobadas por el poder legislativo o el poder ejecutivo —este último siempre y cuando le haya sido delegado conforme a la Constitución y dentro de los límites formales ${ }^{14}$-, se puede regular la carrera administrativa, la cual constituye un bien jurídico constitucional; reconociéndose así una reserva de ley material ${ }^{15}$. En ese orden

12 Lizárraga, Víctor. El derecho disciplinario en la administración pública. Lima: Grijley, 2013; p. 19.

13 El Contralor General de la República, Fuad Khoury Zarzar, presentó el 8 de agosto de 2013 al Congreso de la República un paquete de propuestas legislativas con el propósito de fortalecer el sistema legal anticorrupción en el país, sugiriendo la incorporación a las altas autoridades de los gobiernos regionales y locales en la potestad sancionadora de la Contraloría General y fortalecer el procedimiento sancionador por responsabilidad administrativa funcional. En ese sentido, la propuesta tiene por finalidad incorporar a los Alcaldes, Regidores, Gobernadores Regionales, y Consejeros Regionales, dentro de la potestad sancionadora, en razón que no son pasibles de control político externo por parte del Congreso de la República, teniendo en la actualidad un control político interno debilitado, que crea una sensación de impunidad en la población. El proyecto a la fecha se encuentra en Comisión de Fiscalización y Contraloría del Congreso de la República.

14 RUÍZ, Juan. Documento de Trabajo N. ${ }^{\circ} 43$ IDL-Justicia Viva. El autor refiere lo siguiente «[n] o debemos olvidar que la potestad del Congreso es una potestad libre, no vinculada ni limitada por nada salvo por la Constitución como en cambio lo está el Gobierno a la hora de dictar un decreto legislativo».

15 «[E]l artículo 40 de la Constitución Política del Perú establece que "la ley regula el ingreso a la carrera administrativa, y los derechos, deberes y responsabilidades de los servidores públicos"». Dicha disposición no hace sino reiterar que toda limitación de un derecho fundamental debe provenir de una ley. 
de ideas el Tribunal ${ }^{16}$ ha señalado:

Dicha reserva legal debía entenderse como una de «acto legislativo», y que la misma no era omnicomprensiva para cualquier tipo de normas a las que el ordenamiento pueda haber conferido el rango de ley — como puede el caso de una ordenanza municipal por ejemplo-, pues se trata de un acto legislativo que garantiza que las restricciones y límites de los derechos constitucionales cuenten necesariamente con la intervención del Poder Legislativo, preservando, además, su carácter general y su conformidad con el principio de igualdad.

Por otro lado, es importante definir si los trabajadores sujetos al régimen de la actividad privada (decreto legislativo 728) que prestan servicios en la administración pública son parte o no de la carrera administrativa. Respecto a la interrogante, el Tribunal ha perdido la oportunidad de definir el estatus de los trabajadores de la actividad privada y su relación con la carrera administrativa. En nuestra opinión, el Tribunal continúa ratificando la posición que el personal del régimen laboral del decreto legislativo 728, no pertenece a la carrera administrativa, porque no poseen un nombramiento, pero sí un contrato de trabajo ${ }^{17}$, por ello se estarían restringiendo algunos derechos de acceso a la función pública como, por ejemplo, el derecho al ascenso.

\section{LA POTESTAD SANCIONADORA DE LA ADMINISTRA- CIÓN EN EL PRECEDENTE}

En esta parte nos concentraremos en analizar los efectos que establecen las contrataciones laborales, por parte de funcionarios y servidores que apliquen modalidades distintas a las que correspondan, generando responsabilidad funcional e incluso responsabilidad civil y analizaremos el fundamento 20 de la sentencia, el cual constituye precedente vinculante:

[...] En efecto, con la finalidad de que se apliquen las sanciones que correspondan, la máxima autoridad de la institución deberá determinar quién o quiénes tuvieron responsabilidad en la elaboración del contrato temporal que fue declarado actualizado en un proceso judicial, para lo cual recurrirán a sus propios documentos internos y de gestión, luego de ello se procederá a proporcionar dicha información a conocimiento de la Oficina de Control Interno de la institución a fin de que se efectúen

16 Fundamento 8 de la sentencia del Tribunal Constitucional recaída en el expediente 05057 2013-PA/TC.

17 De acuerdo a lo tipificado por el artículo 4 de la Ley de Productividad y Competitividad Laboral se establece que el contrato de trabajo tiene tres elementos básicos para su existencia, los mismos que son la prestación personal de servicios, la remuneración y la subordinación. 
las investigaciones del caso, se lleve a cabo el procedimiento administrativo disciplinario del personal que incumplió las normas que regulan los requisitos para la contratación del personal en la administración pública, y se establezcan las sanciones pertinentes conforme a lo dispuesto en los artículos $46^{\circ}$ y $47^{\circ}$ Ley N. ${ }^{\circ} 27785$, Orgánica del Sistema Nacional de Control y de la Contraloría General de la República, incorporados por la Ley N. ${ }^{\circ} 29622$, que modifica y amplía las facultades en el proceso para sancionar en materia de responsabilidad administrativa funcional. Una vez determinadas las respectivas responsabilidades, las sanciones que se impongan deberán ser consignadas en el Registro de Sanciones de Destitución y Despido (RSDD), artículo $50^{\circ}$ de la mencionada Ley $N .^{\circ} 27785$.

\subsection{La finalidad de la sanción}

La sanción en el ámbito de la responsabilidad administrativa funcional y disciplinaria tiene por finalidad proteger bienes jurídicos relacionados con la buena administración, además constituye un instrumento de prevención y represión de las conductas de los funcionarios y servidores en procura de la protección del interés general ${ }^{18}$. En ese sentido, la sanción administrativa no debe enfocarse desde el punto de vista punitivo o draconiano contra los funcionarios encargados de los procesos de contrataciones de personal para la administración pública, como el que pretende enfocar el Tribunal en el precedente, al ordenar a las «máximas autoridades de la institución públicas a determinar quién o quiénes tuvieron responsabilidad en la elaboración del contrato temporal que fue declarado desnaturalizado en un proceso judicial, para lo cual recurrirán a sus propios documentos internos y de gestión».

Sobre el particular, el Tribunal no ha tomado en consideración que el procedimiento administrativo disciplinario se divide en dos fases: instructiva y sancionadora. La primera tiene por finalidad buscar la verdad material a través de la investigación y la actuación probatoria y la segunda es la

18 El Tribunal Constitucional, en el fundamento 11 de la sentencia recaída en el expediente 01873-2009-PA/TC, señala que «el objeto del procedimiento administrativo sancionador es investigar y, de ser el caso, sancionar supuestas infracciones cometidas como consecuencia de una conducta ilegal por parte de los administrados. Si bien la potestad de dictar sanciones administrativas al igual que la potestad de imponer sanciones penales, derivan del ius puniendi del Estado, no pueden equipararse ambas, dado que no sólo las sanciones penales son distintas a las administrativas, sino que los fines en cada caso son distintos (reeducación y reinserción social en el caso de las sanciones penales y represiva en el caso de las administrativas). A ello hay que agregar que en el caso del derecho administrativo sancionador, la intervención jurisdiccional es posterior, a través del proceso contencioso administrativo o del proceso de amparo, según corresponda». (El énfasis es propio). 
instancia encargada de sancionar respetando el principio de razonabilidad y proporcionalidad; en ese sentido para el inicio de la fase instructiva se debe tener en consideración lo establecido en el régimen disciplinario regulado en la Ley del Servicio Civil, de obligatoria aplicación en la administración pública a partir del 14 de setiembre de 2014.

\subsection{El inicio del procedimiento disciplinario en la Ley SERVIR}

En la Ley N. $^{\circ} 30057$, en adelante la Ley, el inicio del procedimiento administrativo disciplinario se inicia de oficio o a pedido de una denuncia formulado por personas natural, que tome conocimiento de la comisión de una falta disciplinaria, el artículo 93.1 de la referida Ley reconoce el «principio de oficialidad u obligatoria», en el sentido que la Administración está en la obligación de pronunciarse sobre la procedencia o no, del inicio del procedimiento administrativo, como consecuencia de la denuncia formulada por los administrados y notificar su decisión, el cual es un acto administrativo sujeto a control jurisdiccional.

Siendo así, el Tribunal parte de un supuesto equivocado, donde entiende que el inicio del procedimiento administrativo disciplinario, está a cargo de los titulares de las entidades, quienes conforme a lo establecido en la Ley, son autoridades sancionadoras ${ }^{19}$, por lo tanto, la sentencia debió precisar que las autoridades instructoras inicien los procedimientos administrativos disciplinarios conforme a sus atribuciones, en el presente caso la secretaría técnica o quien haga sus veces.

Cabe mencionar, que la Ley establece que las autoridades del procedimiento contarán con el apoyo de un Secretario Técnico ${ }^{20}$, que debe ser de preferencia un abogado, quien realizará labores correspondientes al órgano de instrucción, es decir, se encargará de impulsar la fase de instrucción y elaborar la propuesta de resolución sobre las actuaciones administrativas más importante, proponiendo la imposición de sanción, ejecutando la actividad probatoria y tipificando las infracciones disciplinarias.

19 Las autoridades del procedimiento administrativo disciplinario regulados en el artículo 92 de la Ley del Servicio Civil son a) el Jefe inmediato del presunto infractor, b) el Jefe de recursos humanos o quien haga sus veces, c) el Titular de la entidad, y d) el Tribunal del Servicio Civil.

20 Cabe mencionar que la Ley del Servicio Civil menoscaba la actuación de los secretarios técnicos al establecer que no tienen capacidad de decisión y sus informes no son vinculantes, hecho que podría poner en peligro la independencia de la etapa de instrucción. 


\section{LA RESPONSABILIDAD ADMINISTRATIVA FUNCIONAL A CARGO DE LA CONTRALORÍA}

En la sentencia se señala que el titular de la entidad procederá a proporcionar información sobre la responsabilidad de los funcionarios encargados de los procesos de contratación de personal, a la Oficina de Control Interno $(\mathrm{OCl})$ de la institución con la finalidad de investigar y llevar a cabo el procedimiento administrativo disciplinario y se establezcan las sanciones pertinentes conforme a lo dispuesto en los artículos 46 y 47 de la Ley N. ${ }^{\circ}$ 27785, Ley Orgánica del Sistema Nacional de Control y de la Contraloría General de la República, incorporados por la Ley N. 29622 , que modifica y amplía las facultades en el proceso para sancionar en materia de responsabilidad administrativa funcional.

En ese sentido, es oportuno precisar algunos conceptos respecto a la potestad sancionadora otorgada a la CGR, para tal efecto analizaremos su constitucionalidad y sus alcances objetivo y subjetivo, para finalmente advertir el error de interpretación por parte del Tribunal.

\subsection{Bases constitucionales de la Ley 29622}

Conforme al artículo 82 de la Constitución Política del Perú, la CGR es una entidad descentralizada de Derecho Público que goza de autonomía conforme a su ley orgánica. Es el órgano superior del Sistema Nacional de Control, encargado de supervisar la legalidad de la ejecución del Presupuesto del Estado, de las operaciones de la deuda pública y de los actos de las instituciones sujetas a control. En ese sentido, el constituyente ha creído por conveniente otorgar la facultad de supervisión a la Contraloría General sobre los actos de legalidad de los funcionarios y servidores públicos, el cual se expresa en el poder sancionador.

Sin embargo, el referido texto constitucional no es suficiente para precisar el deber constitucional de la CGR. En la lucha contra la corrupción, es necesario remitirse al bloque constitucional de la Ley $N .^{\circ} 27778$, expresada en el artículo 16, donde

[l]a Contraloría General es el ente técnico rector del Sistema Nacional de Control, dotado de autonomía administrativa, funcional, económica y financiera, que tiene por misión dirigir y supervisar con eficiencia y eficacia el control gubernamental, orientando su accionar al fortalecimiento y transparencia de la gestión de las entidades, la promoción de valores y la responsabilidad de los funcionarios y servidores públicos, así como, contribuir con los Poderes del Estado en la toma de decisiones y con la ciudadanía para su adecuada participación en el control social. 
Asimismo, la Ley 29622 ha incorporado en el cumplimiento de las funciones de CGR la potestad sancionadora a los funcionarios o servidores públicos que comentan infracción contra la administración pública y en la que se derive responsabilidad administrativa funcional.

Para García ${ }^{21}$, los fundamentos de la constitucionalidad de la potestad sancionadora otorgada a la CGR consisten en que la «atribución corresponde a la modalidad de control gubernamental de legalidad directamente vinculada con la función de la Contraloría General de cautelar los recursos del Estado, promover los valores y la responsabilidad de los funcionarios y servidores públicos y la prevención de la corrupción». Sobre el particular, se considera que la CGR, como un organismo autónomo en cumplimiento de su misión y deber institucional de control de la ejecución presupuestaria, deberá actuar respetando los principios y garantías del procedimiento administrativo sancionador; su actuación no será inconstitucional si en el desarrollo del ejercicio del poder sancionador se respetan los derechos fundamentales de los administrados.

En consecuencia, si la Carta Magna no señala de manera taxativa que la CGR cuente con facultad sancionadora, tampoco prohíbe que la CGR pueda sancionar y ello debido a que la potestad sancionadora forma parte de las competencias asignadas a la Administración Pública y que no solo compatibilizan con la facultad directriz del empleador, sino que, además, encuentra su fundamento en la preservación y autoprotección de la organización administrativa y en el correcto funcionamiento de los servicios público-administrativos

La Comisión Especial Multipartidaria Permanente del Congreso de la República, encargada del control, seguimiento y evaluación al Plan Nacional de Lucha contra la Corrupción, en la Moción de Orden del Día 8445, concluye

[...] [se] considera que el otorgamiento de facultad sancionadora a la Contraloría General de la República significará una importante reforma en el Sistema Nacional de Control, la que permitirá coadyuvar en la lucha contra la corrupción, lo que no importa que se reemplace en sus funciones al Ministerio Público o al Poder Judicial por cuanto se trata de responsabilidad administrativo funcional y no responsabilidad civil o penal, siendo que conforme lo dispone la Ley № 27444 existe autonomía de responsabilidades, es decir, las consecuencias civiles, penales o admi-

21 García, Erika. Análisis de constitucionalidad de la facultad de la Contraloría General de la República para sancionar por responsabilidad funcional y su relación con el principio «Ne bis in ídem» [Tesis de Maestría]. Lima: 2013. Recuperado de: http://tesis.pucp.edu.pe/repositorio/handle/123456789/751/browse?value =Garc\%C3\%ADa + Cobi\%C3\%A1 n+Castro\%$2 \mathrm{C}+$ Erika\&type $=$ author . 
nistrativas de la responsabilidad de las autoridades son independientes y se exigen de acuerdo a lo previsto en su respectiva legislación [...].

\section{2. Ámbito de aplicación subjetivo y objetivo}

El artículo 45 de la Ley 27785, modificado por la Ley 29622, establece el ámbito de aplicación subjetiva:

[...] La referida potestad para sancionar se ejerce sobre los servidores y funcionarios públicos a quienes se refiere la definición básica de la novena disposición final, con prescindencia del vínculo laboral, contractual, estatutario, administrativo o civil del infractor y del régimen bajo el cual se encuentre, o la vigencia de dicho vínculo con las entidades señaladas en el artículo $3^{\circ}$, salvo las indicadas en su literal g) [...].

Asimismo, se establece que se encuentran excluidos las autoridades elegidas por votación popular, los titulares de los organismos constitucionalmente autónomos y las autoridades que cuentan con la prerrogativa del antejuicio político, cuya responsabilidad administrativa funcional se sujeta a los procedimientos establecidos en cada caso.

En relación al ámbito de aplicación objetiva, se reconoce en el reglamento de la Ley 29622 lo siguiente:

[...] El presente Reglamento regula el procedimiento administrativo sancionador (en adelante, el procedimiento sancionador), aplicable por las infracciones graves y muy graves derivadas de los Informes de Control emitido por los órganos del Sistema Nacional de Control, que impliquen el incumplimiento del ordenamiento jurídico administrativo, las normas internas de las entidades, así como de todas aquellas obligaciones derivadas del ejercicio del cargo, conforme a lo dispuesto en el presente Reglamento [...].

El reconocimiento de la responsabilidad administrativa funcional a cargo de la CGR, que se encargará de sancionar o inhabilitar a los funcionarios y servidores públicos que comentan infracciones graves y muy graves derivadas de los Informes de Control, es un medio para enfrentar la corrupción y luchar contra la impunidad en la administración pública.

\subsection{La responsabilidad administrativa funcional y disciplinaria desde la perspectiva del Tribunal}

El Tribunal no tiene clara la diferencia entre responsabilidad administrativa disciplinaria y responsabilidad administrativa funcional, lo cual queda evidenciado cuando se establece que el $\mathrm{OCl}$ de la entidad es el encargado 
de llevar a cabo el «procedimiento administrativo disciplinario». Estas funciones - conforme lo hemos señalado líneas arriba - son parte de la fase instructiva y se encuentran a cargo del órgano instructor de la CGR, el cual está encargado de realizar las actuaciones conducentes a la determinación de la responsabilidad administrativa funcional, que ordenará la práctica de las diligencias que resulten permitentes y adoptará las medidas necesarias para asegurar el deslinde de responsabilidades de los funcionarios y servidores públicos identificados en los informes de control emitidos por los órganos del Sistema Nacional de Control.

Por lo tanto, no es función del $\mathrm{OCl}$ desarrollar la fase instructiva, lo que sí le corresponde es elaborar un informe de control, donde puede identificar las responsabilidades penal, civil y administrativa funcional, insumo básico para el inicio del procedimiento administrativo sancionador a cargo de la CGR.

Es insoslayable referirse al último párrafo del fundamento 20 del precedente, donde el Tribunal por primera vez reconoce la potestad sancionadora a cargo de la CGR como medio de lucha contra la impunidad y la corrupción, lo cual fortalece las funciones de los órganos encargados del procedimiento administrativo sancionador y la labor del Tribunal Superior de Responsabilidades Administrativas (en adelante, TSRA).

[...] Al respecto, cabe precisar que conforme al artículo $11^{\circ}$ y la Novena Disposición Final de la Ley N. ${ }^{\circ} 27785$, los servidores y funcionarios públicos incurren en responsabilidad administrativa funcional cuando contravienen el ordenamiento jurídico administrativo y las normas internas de la entidad a la que pertenecen o cuando en el ejercicio de sus funciones hayan realizado una gestión deficiente. Se desprende que, a su vez, incurren en responsabilidad civil cuando, por su acción u omisión, hayan ocasionado un daño económico al Estado, siendo necesario que este sea ocasionado por incumplir sus funciones, por dolo o culpa, sea ésta inexcusable o leve.

Finalmente, en el fundamento 2.16 del Acuerdo Plenario 001-2013-CG/ TSRA, el TSRA diferencia entre la responsabilidad administrativa funcional y disciplinaria, que constituye así un importante aporte en el desarrollo del derecho disciplinario porque permite diferenciar el poder sancionador de las entidades públicas y la CGR en la misión de proteger los principios de buena administración. Sobre el particular, se han presentado opiniones respetables que cuestionan el referido Acuerdo Plenario ${ }^{22}$, enfocadas es-

22 VIGNOLO, Orlando. "La reducción a la mínima expresión del non bis in idem en el régimen disciplinario peruano». En DANÓS, Jorge, HUAPAYA; Ramón, ROJAS, Verónica, TIRADO, José y Orlando VIGNOLO (coordinadores). Derecho Administrativo: Innovación, cambio y eficacia. Lima: Caballero Bustamante, 2014; p. 407. El autor refiere que «[e]ntonces, el 
pecialmente en la inaplicación del principio del non bis in ídem, que será motivo de análisis en otro trabajo.

Cuadro comparativo entre el procedimiento administrativo sancionador por responsabilidad disciplinaria y el procedimiento administrativo por responsabilidad funcional

\begin{tabular}{|c|c|c|}
\hline & $\begin{array}{c}\text { Procedimiento sancionador } \\
\text { por responsabilidad } \\
\text { administrativa disciplinaria }\end{array}$ & $\begin{array}{l}\text { Procedimiento sancionador } \\
\text { por responsabilidad } \\
\text { administrativa funcional }\end{array}$ \\
\hline $\begin{array}{l}\text { Autoridad } \\
\text { competente }\end{array}$ & $\begin{array}{l}\text { Titular de cada entidad. } \\
\text { Segunda Instancia: Tribunal de } \\
\text { SERVIR. }\end{array}$ & $\begin{array}{l}\text { CGR. } \\
\text { Primera instancia: Órgano Instructor, } \\
\text { Segunda instancia: Órgano Sancionador. }\end{array}$ \\
\hline $\begin{array}{l}\text { Sujetos del } \\
\text { procedimiento }\end{array}$ & $\begin{array}{l}\text { Servidor o funcionario público } \\
\text { que mantiene una relación de } \\
\text { subordinación con la entidad en } \\
\text { el cual ejerce sus funciones. }\end{array}$ & $\begin{array}{l}\text { Servidor o funcionario público que inde- } \\
\text { pendientemente del régimen laboral en } \\
\text { que se encuentra, mantiene el vínculo } \\
\text { laboral, contractual o relación de cual- } \\
\text { quier naturaleza. }\end{array}$ \\
\hline Tipificación & $\begin{array}{l}\text { Faltas disciplinarias desarrolla- } \\
\text { das generalmente de manera } \\
\text { abierta. }\end{array}$ & $\begin{array}{l}\text { Conductas infractoras desarrolladas en } \\
\text { forma descriptiva, exhaustiva. }\end{array}$ \\
\hline $\begin{array}{l}\text { Finalidad de } \\
\text { la sanción }\end{array}$ & $\begin{array}{l}\text { Castigar el incumplimiento de } \\
\text { funciones que respecto de una } \\
\text { determinada actividad consti- } \\
\text { tuye falta en la prestación del } \\
\text { servicio a favor del empleador. }\end{array}$ & $\begin{array}{l}\text { Castigar hechos que configuran respon } \\
\text { sabilidad administrativa funcional, por } \\
\text { la comisión de las conductas tipificadas } \\
\text { como infracciones en la Ley } 27785 \\
\text { modificada por la Ley } 29622 \text { y su Re- } \\
\text { glamento. }\end{array}$ \\
\hline $\begin{array}{l}\text { Finalidad de } \\
\text { la potestad }\end{array}$ & $\begin{array}{l}\text { Asegurar que las actividades } \\
\text { que desarrollan en el marco } \\
\text { de sus funciones se ejerzan en } \\
\text { cumplimiento de la normativa } \\
\text { aplicable, sin perjuicio del po- } \\
\text { der público de tutela del interés } \\
\text { general. }\end{array}$ & $\begin{array}{l}\text { Tutelar el interés público respecto a la } \\
\text { correcta gestión y uso de los recursos } \\
\text { públicos en estricta observancia a los } \\
\text { parámetros que impone el principio de } \\
\text { la Buena Administración frente a con- } \\
\text { ductas que privilegian intereses distinti- } \\
\text { tos de aquel. }\end{array}$ \\
\hline
\end{tabular}

Fuente: Elaboración propia conforme al fundamento 2.16 del Acuerdo Plenario 001-2013-CG/TSRA

Acuerdo Plenario n. ${ }^{\circ} 01-2013-C G / T S R A$ confunde la naturaleza de su propio régimen sancionador (su esencia disciplinaria), al hacerlo pivotar en torno a la jerarquía y subordinación laboral del empleado público respecto a la extraña noción del Estado empleador, construcción que no da cobertura a la potestad explicada, y, por lo demás, frente a la cantidad de sistemas de empleo público que actualmente tenemos...». 


\section{CONCLUSIONES}

La sentencia emitida por el Tribunal y recaída en el expediente 050572013-PA/TC ratifica los principios de meritocracia y reconoce a la carrera administrativa como bien jurídico constitucional, sobre los cuales el mismo Tribunal, los órganos jurisdiccionales y el SERVIR venían aplicando como parte de su fundamentación en sus resoluciones respecto a los referidos principios.

El reconocimiento de la responsabilidad administrativa funcional a cargo de la CGR es un aporte fundamental en la lucha contra la corrupción al interior de la administración pública, el cual fortalece el sistema anticorrupción en el Perú. 